\title{
Recanalization and reperfusion in acute ischemic stroke David S Liebeskind
}

Address: University of California at Los Angeles Stroke Center, 710 Westwood Plaza, Los Angeles, CA 90095, USA

Email: davidliebeskind@yahoo.com

FI000 Medicine Reports 2010, 2:7I (doi:I0.3410/M2-7I)

The electronic version of this article is the complete one and can be found at: http://fl000.com/reports/medicine/content/2/7 I

\begin{abstract}
Revascularization remains the most intuitive strategy to reverse ischemic injury associated with arterial occlusion in acute stroke. Revascularization may lead to opening of an occluded artery, or recanalization, yet restoration of downstream flow, or reperfusion, may not ensue. Revascularization strategies and novel devices continue to broaden options for the treatment of acute stroke, but it is increasingly apparent that selection criteria to identify ideal cases are needed to refine triage and minimize adverse events. The results of recent work on reperfusion may rapidly alter routine clinical practice for evolving ischemia in the brain.
\end{abstract}

\section{Introduction and context}

Ischemia in the brain may result from diverse mechanisms, although blockage of an artery with a clot or progressive narrowing due to atherosclerosis is the most common. Such occlusions in proximal arteries at the base of the brain may be targeted with numerous revascularization approaches, from systemic thrombolysis to endovascular clot manipulation, in order to restore perfusion. Revascularization remains the most intuitive strategy to reverse ischemic injury associated with arterial occlusion in acute stroke [1]. Revascularization may lead to opening of an occluded artery, or recanalization, yet restoration of downstream flow, or reperfusion, may not ensue (Figure 1) [2]. Novel devices and related procedures are rapidly evolving, but effective reperfusion with reversal of all neurological deficits remains an elusive goal [3].

\section{Recent advances}

The last year has yielded several important publications relating to the quandary over current limits in reperfusion for acute ischemic stroke. The natural focus is often placed on the type of device or drug used, ascribing blame or credit to this one piece of the puzzle. Much remains unclear, however, in such comparisons regarding one mode of therapy or another.
The potential biases and need to maintain equipoise were recently reinstated in a detailed overview of the topic [4]. It has been argued that equipoise should be bolstered by enrolling patients in clinical trials that successively incorporate new interventions [4].

The potential role of intravenous thrombolysis for recanalization of various occlusion sites has also been examined in depth [5]. In the Echoplanar Imaging Thrombolytic Evaluation Trial, intravenous tissue plasminogen activator administered in the 3- to 6-hour time window showed poor recanalization of intracranial carotid artery (ICA) lesions and far better results with middle cerebral artery (MCA) occlusions [5]. The treatment benefit of tissue plasminogen activator over placebo in limiting infarct evolution was greater for MCA than for ICA obstruction $(P=0.060)$. Good clinical outcome was also more likely with MCA than with ICA occlusion $(P=0.005)$. It should be noted that these definitions were based on noninvasive magnetic resonance angiography.

This pattern of better recanalization in MCA lesions was observed in univariate analyses of another study that looked at occurrence and predictors of futile endovascular recanalization [6]. Interestingly, however, the role of occlusion site disappeared in multivariate regression 
Figure I. Perfusion angiography of revascularization

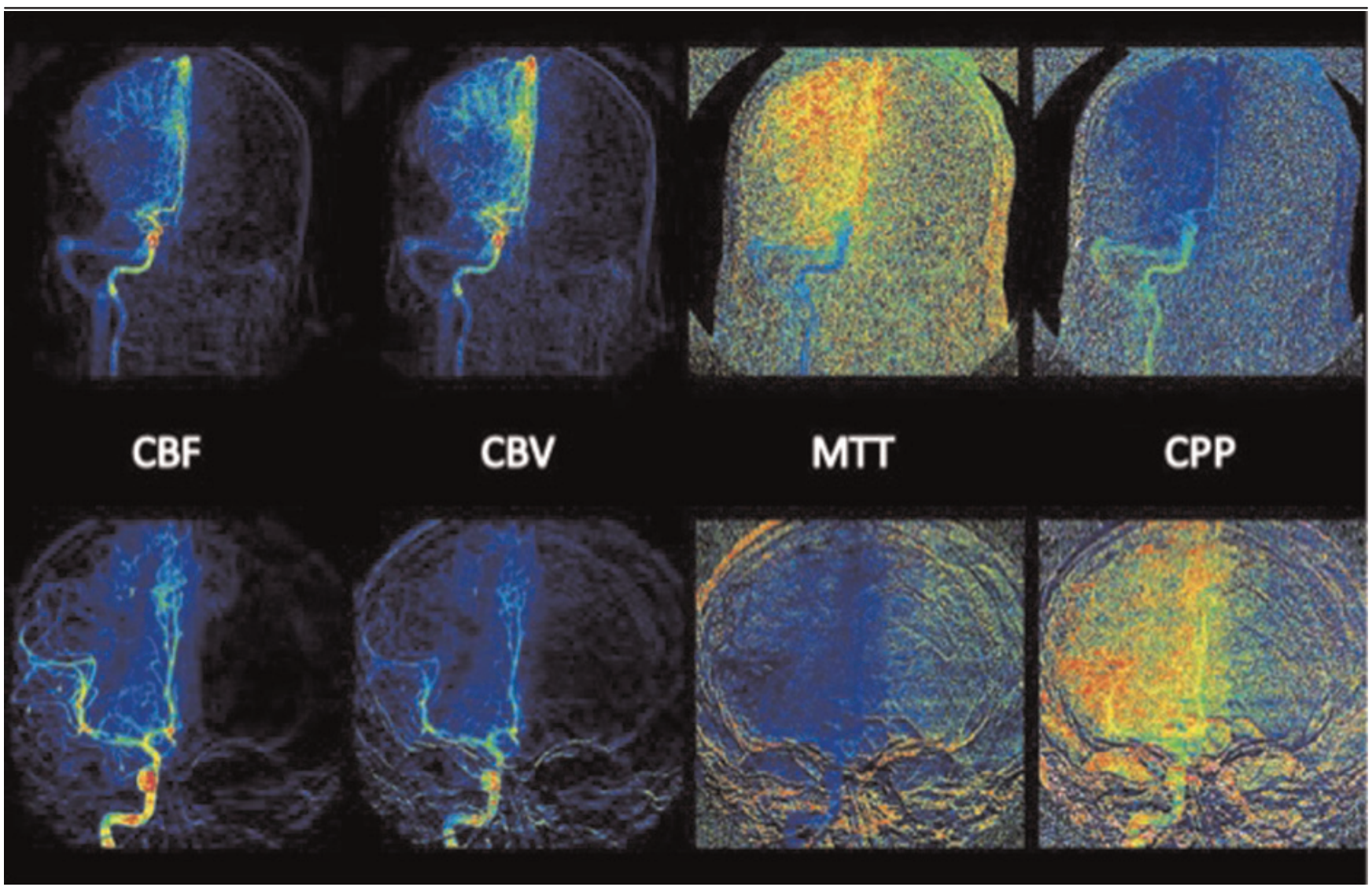

This novel method to measure blood flow from conventional angiography chronicles both recanalization and associated reperfusion in acute stroke. Baseline (top row) and post-revascularization (bottom row) images display changes in cerebral blood flow (CBF), cerebral blood volume (CBV), mean transit time (MTT), and cerebral perfusion pressure (CPP).

in which only age and baseline stroke severity were influential in predicting failed recanalization [6]. Futile recanalization was associated with age of more than 70 years (odds ratio [OR] 4.4, 95\% confidence interval [CI] 1.9-10.5; $P=0.0008$ ) combined with an initial National Institutes of Health Stroke Scale (NIHSS) score of 10-19 (OR 3.8, 95\% CI, 1.7-8.4; $P=0.001$ ), and an initial NIHSS score of 20 or more (OR 64.4, 95\% CI 28.8-144; $P<0.0001)$ regardless of age. Perhaps the extent of early ischemic changes in baseline imaging may be influential, as well [7]. Patients with a baseline NIHSS score of 10-19 may in fact be ideal candidates for endovascular interventions if the patients have small cores with proximal occlusions.

Accurate predictors of futile recanalization may be important in tailoring endovascular procedures and knowing when to cease attempts at opening an artery. Another study looked at the critical number of passes to be used with the Merci Retriever System (Concentric
Medical, Inc., Mountain View, CA, USA), noting that more than three thrombectomy attempts may be the cutoff [8]. When at least four attempts were performed, the final result was more often failed revascularization and procedural complications $(P=0.006)$ [8].

Such limitations with novel devices must be considered as new technology and methods are introduced. A recent report on the use of the Enterprise stent (Cordis Corporation, Bridgewater, NJ, USA) in just over a handful of patients reported successful angiographic reperfusion scores in all, yet the limitations of the scale parameter used (e.g., Thrombolysis in Cerebral Infarction [TICI] score of 2 or more) may not be synonymous with full reperfusion [9].

Another study demonstrated appropriately defined reperfusion success, defining successful reperfusion as a TICI grade of $2 \mathrm{~b}$ or 3 in 18 of $20(90 \%)$ vessels treated with the Solitaire stent (ev3 Inc., Plymouth, MN, USA) 
[10]. Baseline imaging patterns, such as the extent of cerebral blood volume abnormalities, have also recently proven to predict fatal outcomes [11] and ultimately may prove to be very important in proper case selection [12]. Presumably, such variation is due to underlying differences in the potential of collateral compensation, and future diagnostic strategies may be able to better discern these key features [13]. Following revascularization, reperfusion more accurately predicts infarct growth than recanalization does [14].

Future interventions, such as decompressive hemicraniectomy, may be used after failed reperfusion. This surgery is currently reserved for life-threatening massive infarcts, yet one group suggested that it may be used at an earlier stage or pre-emptively or as early as possible in cases of failed multimodal therapy [15].

Finally, understanding the basic mechanisms of reperfusion and improved approaches is also under study. Mechanisms such as ischemic post-conditioning, in which gradual reperfusion is employed to obtain optimal reperfusion, are worthy of further study [16].

\section{Implications for clinical practice}

Revascularization strategies and novel devices continue to broaden options for the treatment of acute stroke, but it is increasingly apparent that selection criteria to identify ideal cases are needed to refine triage and minimize adverse events [17]. Recent study results reinforce the need to be wary of trial results as the definitions of reperfusion may vary considerably [18]. Distinctions between recanalization and reperfusion should be noted. Furthermore, specific angiographic scale features and thresholds to measure success should be scrutinized. This focus on reperfusion is warranted because it is the closest surrogate of clinical outcome and the results of recent work on reperfusion may rapidly alter routine clinical practice for evolving ischemia in the brain. The topic of reperfusion is greatly expanding along molecular mechanisms to animal models to increasing attention in stroke cases subject to revascularization. Finally, it should not be forgotten that clinical outcome is ultimately what matters most. Randomized controlled studies have yet to unequivocally demonstrate that novel revascularization and prompt reperfusion impact outcome.

\section{Abbreviations}

$\mathrm{CI}$, confidence interval; ICA, intracranial carotid artery; MCA, middle cerebral artery; NIHSS, National Institutes of Health Stroke Scale; OR, odds ratio; TICI, Thrombolysis in Cerebral Infarction.

\section{Competing interests}

The author declares that he has no competing interests.

\section{Acknowledgments}

This work was supported by funding from National Institutes of Health-National Institute of Neurological Disorders and Stroke awards K23 NS054084 and P50 NS044378.

\section{References}

I. Liebeskind DS: Reperfusion for acute ischemic stroke: arterial revascularization and collateral therapeutics. Curr Opin Neurol 2010, 23:36-45.

2. Khatri P, Neff J, Broderick JP, Khoury JC, Carrozzella J, Tomsick T: Revascularization end points in stroke interventional trials: recanalization versus reperfusion in IMS-I. Stroke 2005, 36:2400-3.

3. Menon BK, Hill MD, Eesa M, Modi J, Bhatia R, Wong J, Hudon ME, Morrish W, Demchuk AM, Goyal M: Initial experience with the Penumbra Stroke System for recanalization of large vessel occlusions in acute ischemic stroke. Neuroradiology 2010, [Epub ahead of print]

4. Tomsick TA, Khatri P, Jovin T, Demaerschalk B, Malisch T, Demchuk A, Hill MD, Jauch E, Spilker J, Broderick JP: Equipoise among recanalization strategies. Neurology 2010, 74:1069-76.

5. De Silva DA, Brekenfeld C, Ebinger M, Christensen S, Barber PA, Butcher KS, Levi CR, Parsons MW, Bladin CF, Donnan GA, Davis SM: The benefits of intravenous thrombolysis relate to the site of baseline arterial occlusion in the Echoplanar Imaging Thrombolytic Evaluation Trial (EPITHET). Stroke 2010, 41:295-9.

6. Hussein HM, Georgiadis AL, Vazquez G, Miley JT, Memon MZ, Mohammad YM, Christoforidis GA, Tariq N, Qureshi Al: Occurrence and predictors of futile recanalization following endovascular treatment among patients with acute ischemic stroke: a multicenter study. AJNR Am J Neuroradiol 2010, 3 I:454-8.

7. Parsons MW, Christensen S, McElduff P, Levi CR, Butcher KS, De Silva DA, Ebinger M, Barber PA, Bladin C, Donnan GA, Davis SM; Echoplanar Imaging Thrombolytic Evaluation Trial (EPITHET) Investigators: Pretreatment diffusion- and perfusion-MR lesion volumes have a crucial influence on clinical response to stroke thrombolysis. J Cereb Blood Flow Metab 2010, 30:1214-25.

FI000 Factor 3.0 Recommended

Evaluated by David Liebeskind 19 Feb 2002

8. Loh Y, Jahan R, McArthur DL, Shi ZS, Gonzalez NR, Duckwiler GR, Vespa PM, Starkman S, Saver JL, Tateshima S, Liebeskind DS, Vinuela F: Recanalization rates decrease with increasing thrombectomy attempts. AJNR Am J Neuroradiol 2010, 31:935-9.

9. Kulcsár Z, Bonvin C, Lovblad KO, Gory B, Yilmaz H, Sztajzel R, Rufenacht $D$ : Use of the enterprise intracranial stent for revascularization of large vessel occlusions in acute stroke. Klin Neuroradiol 2010, [Epub ahead of print].

10. Castaño C, Dorado L, Guerrero C, Millán M, Gomis M, Perez de la Ossa N, Castellanos M, García MR, Domenech S, Dávalos A: Mechanical thrombectomy with the Solitaire AB device in large artery occlusions of the anterior circulation. A pilot study. Stroke 2010, 41:1836-40.

II. Kim JT, Park MS, Choi KH, Nam TS, Choi SM, Lee SH, Kim BC, Kim MK, Cho KH: The CBV-ASPECT Score as a predictor of fatal stroke in a hyperacute state. Eur Neurol 2010, 63:357-63. 
12. Mishra NK, Albers GW, Davis SM, Donnan GA, Furlan AJ, Hacke W, Lees KR: Mismatch-based delayed thrombolysis: a metaanalysis. Stroke 20I0, 4I:e25-33.

FI000 Factor 6.0 Must Read

Evaluated by Carlos Kase 25 Feb 2002

13. Zhang $\mathrm{H}$, Prabhakar P, Sealock R, Faber JE: Wide genetic variation in the native pial collateral circulation is a major determinant of variation in severity of stroke. J Cereb Blood Flow Metab 2010, 30:923-34.

14. Soares BP, Tong E, Hom J, Cheng SC, Bredno J, Boussel L, Smith WS, Wintermark M: Reperfusion is a more accurate predictor of follow-up infarct volume than recanalization: a proof of concept using ct in acute ischemic stroke patients. Stroke 2010, 4I:e34-40.
I5. Arkadir D, Eichel R, Cohen JE, Itshayek E, Gomori JM, Ben-Hur T, Rosenthal G, Leker RR: Decompressive hemicraniectomy improves outcome in patients with failed arterial recanalization after acute carotid artery occlusion. Neurol Res 2010, [Epub ahead of print].

16. Zhao $\mathrm{H}$ : Ischemic postconditioning as a novel avenue to protect against brain injury after stroke. J Cereb Blood Flow Metab 2009, 29:873-85.

17. Alexandrov AV: Current and future recanalization strategies for acute ischemic stroke. J Intern Med 2010, 267:209-19.

18. Higashida RT, Furlan AJ, Roberts H, Tomsick T, Connors B, Barr J, Dillon W, Warach S, Broderick J, Tilley B, Sacks D: Trial design and reporting standards for intra-arterial cerebral thrombolysis for acute ischemic stroke. Stroke 2003, 34:el09-37. 